\title{
Frequency of Lingual Nerve Injury after the Removal of Impacted Mandibular Third Molar
}

Farzana Kalsoom ${ }^{1}$, Farah Farhan², Saima Munir ${ }^{3}$, Rizwana Durrani ${ }^{4}$, Sohail Fareed ${ }^{5}$, Khalil Ahmad Khan ${ }^{6}$

1. Head Of Department, Hitec Dental College, Taxilla

2. Assistant Professor, Department of Oral Pathology, Foundation College of Dentistry, Islamabad

3,5,6. Department of Oromaxilofacial Surgery, Nishtar Institute of Dentistry, Multan

4. PMO, Peace General Hospital, Islamabad

Corresponding Author: farzanakulsoom97@hotmail.com

\begin{abstract}
Objective: to determine the frequency of lingual nerve injury after the removal of impacted mandibular 3rd molar. Study Design: Cross sectional study Place and duration: outdoor patient department of Oral and Maxillofacial Surgery Hitec Dental College, Foundation College of Dentistry Peace Gernal Hospital, Nishtar Institute of Dentistry,Multan from January 2018 to January 2019 in one year duration. Results: Study included 335 patients with mean age of $20.86+1.95$ yrs. Males were $190(56.7 \%)$ and females were $145(43.3 \%)$ ).lingual nerve injury was found in 28 patients $(8.4 \%)$ while it was absent in 307 patients(91.6\%). There was no significant effect was found on the frequency of lingual nerve injury for age or gender of the patient population. Conclusion: Lingual nerve injury is a commonly encountered complication among those undergoing extraction of impacted third molar. It should be carefully sought in all the patients undergoing the surgical procedure and improvement in surgical skills and techniques needs to be emphasized to further reduce the incidence and risk of this complication.
\end{abstract}

Keywords: Impacted third molar, Lingual nerve, OPG (orthopantomogram), Dentistry, Mandible.

DOI: $10.7176 / \mathrm{JMPB} / 57-01$

Publication date: July $31^{\text {st }} 2019$

\section{Introduction:}

The impacted third molar is sometime fails to break throghthe dental arch within normal time of expectation ${ }^{1}$, so extraction of third molar teeth is common and most frequent surgical procedure in dental surgery ${ }^{2}$. The reason for extraction includes presence of presence of cyst or tumor, pericoronitis acute or chronic, carious lesion on molar teeth may be $2^{\text {nd }}$ or $3^{\text {rd }}$ molar, periodontal problems and in the preparation for orthodontic treatment or orthognathic surgery ${ }^{3}$.

Injury of somatosensory branches supplied by the trigeminal nerve is the common risk associated with removal of third molar. Main branches of trigeminal nerve on risk are inferior alveolar nerves and lingual nerve $e^{4}$. Contributing factors of complications of this surgical procedure are medical history, age, old age, use of oral contraceptives, smoking, pericoronitis, poor hygiene, type of impaction, contact of lingual nerve and inferior alveolar nerve with third molar, anesthetic technique, surgeon's experience, technique used for procedure, duration of procedure, use f preoperative antibiotics and intra socket medication ${ }^{5}$. Clinical and radiological evaluation of third molar is necessary before removal of third molar teeth to avoid or minimize the expected complications ${ }^{6,7}$.

Hippocrates and Plato described about wisdom tooth in ancient times approximately in $20^{\text {th }}$ century. Daily advancement in anesthesia techniques, modern radiology, experienced hands and sterile technique made it easier to remove wisdom tooth ${ }^{8}$. Latest goals in dental surgery are to remove dental diseases and provide healthy oral and dental care for the well being of humanity ${ }^{9}, 10$. Theoretical learning and implementation of this knowledge in clinical practice repeatidly reduce the injury to lingual nerve during soft tissue flap $\mathrm{p}^{11,12}$.

The rationale of the present clinical prospective study is to determine the frequency of lingual nerve injury following mandibular third molar extraction and to analyze and document possible factors for the lingual nerve injury. By the help of this study we will be able to give certain methods for preservation of lingual nerve like use of Howarth periosteal elevator for retraction of lingual flap, extraction without elevation of lingual flap or retention of lingual plate.

Methodology:

Patients were included from outdoor patient department of Oral and Maxillofacial Surgery Hitec Dental College, Foundation College of Dentistry Peace Gernal Hosptal, Nishtar Institute of Dentistry,Multan from January 2018 
to January 2019 in one year duration, on the basis of history,clinical and radiographical examination evaluated by researcher. OPG and periapical radiograph were done. Study was started after taking informed consent from patient and approval of ethical committee. Data collected for each patient including age, sex and medical status at the time of procedure. Patients with intact lingual nerve, gender with impacted mandibular third molar and age between 18-24 yrs, all classes and positions of impacted third molar were included in the study. Diabetes endocrine pathologies, immune suppression, cardiovascular pathologies, nutritional and/or neurological alterations, impacted third molar associated with cyst or tumor, impacted third molar within the line of fracture of angle of mandible were excluded from the study.

Nerve injury was assessed after 24 hours of extraction by checking gustatory sensation over anterior two third of tongue using 2 solutions with different concentration of $\mathrm{NaCl}(1.01 \mathrm{~mol} / \mathrm{L}, 1.51 \mathrm{~mol} / \mathrm{L}, 2.01 \mathrm{~mol} / \mathrm{L})$ presented in 5 $\mathrm{ml}$ sample. This solution prepared with very small concentrations. Filter paper disc with $5 \mathrm{~mm}$ diameter was A $5 \mathrm{~mm}$ diameter filter paper disc was instilled and maintained in 5 seconds duration. If no response was observed patients were asked to wash and rinse the mouth with clean water and after 30 seconds test was repeated. In next attempt solution concentration was increases and increases progressively until test was not recognized. Sensory sensation was assessed on opposite site of procedure. The non operated site was used as control. Sensory sensations were assessed on that side by checking pressure, pain and two point discrimination while non operating site used as control. This function was studied pre operatively and after 24 hours of extraction.

SPSS version 23 was used for determination of data variables. Variables were analyzed and presented in the form of frequency, proportions and percentage. Qualitative/categorical variables in demographic data like gender and nerve injury were presented as percentage and frequency. Whereas quantitative/continuous data like age was presented as mean with standard deviation. Chi-square test was applied. P-value $\leq 0.05$ was taken as significant.

\section{Results:}

Total 335 patients with mean age of $20.86+1.95$ years ranging from a minimum of 18 years to maximum 24 years were included in study. Males were 190(56.7\%) while females were 145(43.3\%).lingual nerve injury was found to be present in 28 patients $(8.4 \%)$ while it was absent in 307 patients( $91.6 \%)($ table: 1$)$

Among 145 females, lingual nerve injury was present in $13 / 145(8.9 \%)$ while it was absent in $132 / 145(91.03 \%)$.on the other hand, among 190 males, lingual nerve injury was present in 15/190(.) while it was absent in 175/190 (92.1\%) When the effect of age was noted it was found that 191 patients were presented in age group of 18-21 years and lingual nerve injury was present in 12/191 patients(6.28\%)while it was absent in $179 / 191$ patients(93.71\%).on the other hand there were 144 patients presented in age group $\geq 22$ years and lingual nerve injury was present in 16/144 patients (11.11\%)while it was absent in 128/144 patients(88.89\%).

Table-1: Demographics And Distribution Of Lingual Nerve Injury

\begin{tabular}{|l|l|}
\hline Total Patients & $\mathbf{3 3 5}$ \\
\hline Male & $190(56.7 \%)$ \\
\hline Female & $145(43.3 \%)$ \\
\hline Mean Age & $20.86 \pm 1.95$ \\
\hline Lingual Nerve Injury & $28(8.4 \%)$ \\
\hline
\end{tabular}

\section{Discussion:}

In 1997 the Faculty of Dental Surgery of Royal College of Surgeons of England described clearly need and time of third molar extraction. It was also well defined whether it will be retained of sacrificed ${ }^{13}$. It was written in literature that surgical removal of third molar associated with swelling, pain, trismus and bruising and must be explained to patients before removal ${ }^{14}$. 
In a study conducted by Carmichael et $\mathrm{al}^{15}$ in 1992 and reported all these complications like swelling and pain. Incidence of lingual nerve damage was observed in $15 \%$ of patients on operated side. Temporary sensory deficit was also observed in some patients. These adverse events sometime not acceptable by patients if not explained and warn before start of operative procedure.

Blackburn et $\mathrm{al}^{16}$ conducted another study on this topic and reported lingual nerve damage in $11 \%$ of patients. This study concluded that main contributing factors of lingual nerve injury are surgeon's experience, technique used for removal of teeth and handling of mucoperiosteal flap with elevator such as raising and retracting proper or improper way

Another study was conducted by Lata et $\mathrm{al}^{17}$ in 2011 and reported $6.6 \%$ lingual nerve injury; six patients were observed diagnosed minor paresthesia on $7^{\text {th }}$ day after surgery. In this study another observation was found that handling of flap not and active issue but anatomical variation of lingual nerve is the matter. Due to this anatomical variation experienced surgeons are not safe from this complication.

Bataineh et $\mathrm{al}^{18}$ in his study observed that lingual nerve injury was occurred in $2.6 \%$ of patients which is a high ratio as compared to previous studies. Almost all cases were reported due to raising or handling of lingual flap. Not only lingual nerve but alveolar nerve injury 3.9\% was also reported in this study. Mostly patients were old aged. Gomes et $\mathrm{al}^{19}$ also conducted a study and reported $9.1 \%$ lingual nerve injury but in control group where flap was not retracted no injury was observed.

Meshram et $\mathrm{al}^{20}$ conducted a study on evaluation of lingual nerve injury in procedure of third molar removal and observed $1.36 \%$ lingual nerve paresthesia, most of patients in this study were male and old aged. In our study we also observed male dominancy and old age factor as contributing in lingual nerve injury.

\section{Conclusion:}

Lingual nerve injury is a commonly encountered complication among those undergoing extraction of impacted third molar. It should be carefully sought in all the patients undergoing the surgical procedure and improvement in surgical skills needs to be emphasized to further reduce the incidence and risk of this complication.

\section{REFERENCES:}

1. Peterson LJ, Ellis E III, Hupp JR, Tucker M R. Contemporary Oral and Maxillofacial Surgery. 4th Ed. Philadelphia: mosby; 2004:184.

2. Contar CM, De Oliveira P, Kanagusuku KB, Azevedo-Alanis LR, Machado MA. Complication in third molar removal: A retrospective study of 588 patients. Med Oral Patol Oral Cir Bucal. 2010;5:74-8.

3. Blondeau F, Daniel NG. Extraction of impacted mandibular third molar: Postoperative complications and their risk factors. J Can Dent Assoc. 2007;73:325.

4. Ridaura-Ruiz L, Figueiredo R, Valmaseda-Castellon E, Berini-Aytes L, Gay-Escoda C. Sensibility and taste alteration after impacted lower third molar extraction: A prospective cohort study. Med Oral Patol Oral Cir Bucal. 2012;17:759-64.

5. Milkawi Z, Al Omiri MK, Khraisat A. Risk indicators of postoperative complications following surgical extraction of lower third molars. Med Princ Pract. 2011;20:321-5.

6. Larsen PE, Mesieha ZS, Peterson LJ, Beck FM. Impacted third molars:radiographic features used to predict extraction difficulty. J Dent Res. 1991;70:551-7.

7. Lodi G, Figini L. Antibiotics to prevent complications following tooth extractions. Cochrane Database Syst Rev. 2012;4(11):21-9.

8. Ghaeminia H. Coronectomy may be a way of managing impacted third molars. Evid Based Dent. 2013;14(2):57-8.

9. Houston JP, McCollum J, Pietz D, Schneck D. Alveolar osteitis:A review of its etiology, prevention and treatment modalities. Gen Dent. 2002;50(5):457-65.

10. Andreasen JO, Peterson JK, Laskin D. Textbook and color atlas of tooth impactions:diagnosis, treatment and prevention. Oxford:Munksgaard;1998:123. 
11. Brann CR, Brickley MR, Shepherd JP. Factors influencing nerve damage during lower third molar surgery. Br Dent J. 1999;186(10):514-6.

12. Nickel Alfred A Jr. A retrospective study of paresthesia of the dental alveolar nerves. Anesth Prog. 1990;37(1):42-5.

13. Bataineh AB, Sensory nerve impairment following mandibular third molar surgery. J Oral Maxillofac Surg. 2001;59(9):1012-7.

14. Peterson DW, Miloro M, G E Ghali. Peterson Principles of Oral \& Maxillofacial Surgery. 2nd Ed. Philadelphia:mosby;2004:6.

15. Carmichael FA, McGowan DA. Incidence of nerve damage following third molar removal: A West OF Scotland Oral Surgery Research Group study. Br J Oral Maxillofac Surg. 1992;30:78-82.

16. Blackburn CW, Bramley PA. Lingual nerve damage associated with the removal of lower third molars. Br Dent J. 1989;167:103-7.

17. Lata J, Tiwari AK. Incidence of lingual nerve paraesthesia following mandibular third molar surgery. Natl J Maxillofac Surg. 2011;2(2):137-40.

18. Bataineh AB. Sensory nerve impairment following mandibular third molar surgery. J Oral Maxillofac Surg. 2001;59(9):1012-7.

19. Gomes AC, Vasconcelos BC, de Oliveira e Silva ED, da Silva LC. Lingual nerve damage after mandibular third molar surgery:a randomized clinical trial. J Oral Maxillofac Surg. 2005;63(10)1443-6.

20. Meshram VS, Meshram PV, Lambade P. Assessment of nerve injuries after surgical removal of mandibular third molar:A Prospective study. Asian J Neurosci. 2013;29:926-32. 